minal motor innervation that can be linked with particular diseases of the lower motor neurone or of the non-neural components of muscle. Their findings in diseases such as myasthenia gravis and dystrophia myotonica indicate a new phase of investigation in a number of hitherto mysterious maladies. It should, however, be appreciated that the intravital technique cannot simply be requested as an addition to routine biopsies. It is essentially a time-consuming and specialized line of research, requiring expertise and prolonged study if rewards are to be obtained. The present volume represents a beginning; it clearly indicates where progress can be made. As such it is assured of a warm welcome.

The book is lavishly illustrated with $28 \mathrm{I}$ figures. Most of these are photomicrographs, including 12 in colour. These give an admirable impression of the scope of the technique and greatly enhance the value of the work, for which, it may be added, the price required is gratifyingly modest.

\section{SYNOPSIS OF EAR, NOSE AND THROAT DISEASES}

By R. E. Ryan, W. C. Thornell and Hans von LEDEN. Pp. 383 , illustrated. St. Louis: The C. V. Mosby Co. Distributed in Great Britain by Henry Kimpton, London. 1959. 50s.

The purpose of the authors of this admirable book, is to present a digest of the common ailments within the specialty, which form such a large percentage of the daily practice of medicine, and to serve as a handy guide for the busy family physician, the intern, the medical student, and a ready reference for nurses and speech therapists. The material is divided into four parts dealing with the ears, the nose and paranasal sinuses, the pharynx, and the larynx.

In their purpose the authors have been admirably successful. The text is well and clearly written and contains all the information on the various sections of the specialty necessary to those sections of undergraduates and postgraduates who do not intend, themselves, to specialise. Each section of the book is followed by an even more condensed summary of the preceding digest, and would be admirable for revision purposes, but should never take the place of the fuller text. The chapters on the external ear, the middle ear, and the nose, are particularly well covered, especially those conditions most commonly encountered in general practice. This does not imply less able or thorough coverage in the other sections, but only that the former are met almost every day in a busy practice. It is reassuring to note that practitioners are well and frequently warned of the dangers of prescribing various drops, sniffs and sprays locally in the nose itself. The condition of rhinitis medicamentosa is, alas, all too commonly seen in the E.N.T. Clinic.

Synopses are always very popular with undergraduates. This one should be no less so than those available in the other subjects covered by the medical curriculum. It is well-bound, clearly printed and illustrated, and is of a convenient size to fit the pocket. It is ventured to suggest that this publication would be useful not only to those members of the profession already mentioned, but also as a means of rapid and easily comprehensible reference to consultants in other specialties.

\section{SYNOPSIS OF GYNECOLOGY}

By Robert James Crossen, M.D., Daniel Winston BEacham, M.D., and WoOdard David Beacham, M.D. Pp. 340, illustrated. St. Louis: The C. V. Mosby Co. Distributed in Great Britain by Henry Kimpton, London. 1959. 48s. $6 \mathrm{~d}$.

This is the $5^{\text {th }}$ edition of a short synopsis which is, in the main, extracted from the well-known gynaecological text book by Crossen and Crossen. So it has ro6 illustrations, nearly all taken from the major text book and reduced in size and it has in synoptic form most of what the non-specialist gynaecologist needs to know about gynaecology.

It is inadequate for any postgraduate examination in this country and, let us confess it, a little oldfashioned in parts, especially in the illustrations, for the undergraduate.

Yet there are some good features such as the beautiful black and white photographs of the Papanicolaou's stains from the vagina in the menstrual cycle.

For a book for revision, to be carried in the pocket it is ideal. Although it has 340 pages, and althoug the paper is absolutely excellent, the book is nof thick. The print is large and the language simple Each chapter has very full references. At $48 \mathrm{~s}$. 6d: it is expensive to buy, but yet probably the best book that there is on gynaecology to read on the top of a London omnibus, caught in the endless traffic jams. I can think of few better text books to use for quick revision, in these circumstances-but only in these circumstances.

\section{HOW TO LEARN MEDICINE}

By A. E. Clark-Kennedy, M.A., M.D., F.R.C.P. Pp. 227. London: Faber \& Faber Ltd. I 959. I 2s. 6d.

'This book contains much wise observation and good advice. Although I am two generations behind Dr. Clark-Kennedy I found many comments with which I wholeheartedly agree, and few with which I disagree. The approach, unfortunately, may be too avuncular for the sophisticated young people entering and passing through medical school. To them I would say 'it is well worth reading, but don't be put off by the style.'

\section{NEW AND NON-OFFICIAL DRUGS, 1959}

London: Pitman Medical Publishing Co. Ltd. I 959. 3os.

Forty-one new monographs are included in the lastest edition of N.N.D., while 12 have been 